\title{
Microscopic Features, Chromatographic Fingerprints and Antioxidant Property of Some Unconventional Green Leafy Vegetables Consumed in Bandundu, DR Congo
}

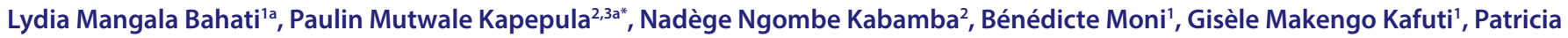 \\ Mbombo Mungitshi' ${ }^{2}$, Aaron Pambu', Gedeon Bongo', Adam Tujibikila Mukuta², Jimmy Kabeya Kabengele², Clement Mbadiko Mutunda', \\ Michel Frederich ${ }^{3}$, Théophile Mbemba Fundu ${ }^{1}$ \\ 'Department of Biology, Faculty of Sciences, University of Kinshasa, P.O. Box 190 Kinshasa XI, Democratic Republic of the CONGO. \\ ${ }^{2}$ Centre d'Etudes des Substances Naturelles d'Origine Végétale (CESNOV), Faculty of Pharmaceutical Sciences, University of Kinshasa, BP 212 Kinshasa XI, Democratic \\ Republic of CONGO. \\ ${ }^{3}$ Laboratory of Pharmacognosy, Center for Interdisciplinary Research on Medicines (CIRM), University of Liège, BELGIUM. \\ NOTE: "a" These authors contributed equally to this article
}

\begin{abstract}
Introduction: Nutrition is an important aspect of public health because it is linked to many significant diseases and health problems. This work is part of the promotion of traditional foods from the Democratic Republic of Congo, particularly in the province of Bandundu, by assessing the antioxidant capacity of 4 unconventional green leafy vegetables and determining their microscopic features and their chromatographic fingerprints. Materials and Methods: Methanolic extracts from leaves of traditional vegetables were characterized for their chemical fingerprint by TLC, HPLC-DAD and their in vitro antioxidant activities using ABTS, DPPH assays. Results: The microscopic analysis of the powder of leaves showed that each species presents characteristic elements allowing their distinction. Phytochemical screening revealed the presence of flavonoids, terpenes, steroids and quinones in all species. However, Entada gigas and Psophocarpus scandens also contain alkaloids, Salacia pynaertii and Tetrochirdium congolenses also contain anthocyanins. All extracts displayed a good radical-scavenging activity at the concentration range $1-60 \mu \mathrm{g} / \mathrm{mL}$ in the following order: S. pynaertii > T. congolense $>$ E. gigas $>$ P. scandens. S. pynaretii and T. congolense extracts showed significant antioxidant activity compared to
\end{abstract}

quercetin, and this activity may depend on a synergic effect of several polyphenolic compounds. Conclusion: The high nutritive value of these traditional vegetables associated with their important antioxidant activities could contribute to diversifying diets for increased antioxidant consumption for Bandundu's population, and could provide benefits for protection against oxidative damage under different conditions including konzo.

Key words: Entada gigas, Konzo, Psophocarpus scandens, Salacia pynaertii, Tetrorchidium congolense, Traditional vegetable.

\section{Correspondence:}

Mr. Paulin Mutwale Kapepula,

Centre d'Etudes des Substances Naturelles d'Origine Végétale (CESNOV),

Faculty of Pharmaceutical Sciences, University of Kinshasa, BP 212 Kin-

shasa XI, Democratic Republic of CONGO.

Phone no: +243810513448

E-mail: garaphmutwal@yahoo.fr

DOI : $10.5530 /$ pc. 2017.4 .23

\section{INTRODUCTION}

Nutrition is an important aspect of public health because it is linked to many significant diseases and health problems. Multiple epidemiologic studies have shown that the consumption of vegetable foods could be a public health issue. Polyphenols are the most abundant antioxidants in the diet, and consumption of foods and beverages containing polyphenols may have significant public health implications. Based on existing research, polyphenols may be useful in primary and secondary prevention, particularly concerning diseases associated with oxidative damage such as obesity, diabetes, cardiovascular disease, and cancers. ${ }^{1}$ Finding alternative and complementary ways to reduce the redox processes might have a beneficial interest in the context of developing countries.

The Flora of Kwilu Kwango in Bandundu area (Democratic Republic of Congo) is rich in traditional foods that are mostly unexploited. For this reason, Mbemba et al assessed the nutritional value of some traditional foods by determining their relative amino acid composition, in order to contribute to the equilibration of the diet in the population of this area severely affected by malnutrition ${ }^{2}$ and diseases such as konzo, a toxico-nutritional neurological disease in which oxidative damage plays a decisive role. ${ }^{3}$ Among traditional foods studied by Mbemba et al, we focus our research on four species of plants commonly used as traditional vegetables to Kenge city in Bandundu area: Entada gigas (L.) Fawc. \& Rendle, Psophocarpus scandens (Endl.) Verdc, Salacia pynaertii De Wild, and Tetrorchidium congolense J.Léonard.

Entada gigas, native from Central America, Caribbean, and Africa, is commonly known as sea heart. It is a vegetable flowering plant of the pea family, Fabaceae. Seeds of E. gigas have not been used by people as food but it is a very popular seed used in the preparation of traditional concoctions for curing diseases in Nigeria. ${ }^{4}$ Young leaves are consumed as a vegetable in DRC where it was called Futi futi or Nzembo futi. ${ }^{2}$ Psophocarpus scandens (Fabaceae) is a vigorous, perennial vine with mauve, blue, lilac or white flowers. The primary use of P. scandens is as food in DRC where it was commonly called kikalakasa. ${ }^{2}$ Salacia pynaertii (Celastraceae) is a liana native of Africa. The young leaves are eaten as a vegetable in DRC and it is called Mbondi in the local language. They are usually pounded and cooked with peanuts, caterpillars or mushrooms and local tomatoes. ${ }^{2,5}$ Tetrorchirdium congolense (Euphorbiaceae) is native to tropical Africa. This plant is used medicinally in Central Africa, where the bark latex is taken with palm wine to treat diarrhea. ${ }^{6}$ It is called in Bandundu local language "Nkelekete. Young leaves are consumed as a traditional vegetable in DRC. ${ }^{2}$

To our knowledge, few investigations have been performed on the phytochemical composition and the biological properties such as antioxidant capacities of these food plants from Bandundu. The present work aimed to determine the microscopic features of these vegetables and to investigate the antioxidant activities of their methanolic extracts using ABTS and DPPH assays. Thin Layer Chromatography (TLC) and High-Performance Liquid Chromatography (HPLC-DAD) were used to achieve phytochemical analysis of phenolic compounds. 


\section{MATERIALS AND METHODS}

\section{Study environment}

Plants have been harvested in Kenge ( $\mathrm{S} 04^{\circ} \mathrm{S} 1^{\prime} \mathrm{E} 16^{\circ} \mathrm{S} 8^{\prime}$ ), a commune in Pelende-Nord sector, Kwango district, Bandundu Province in the Democratic Republic of the Congo.

\section{Plant materials}

The leaves of Psophocarpus scandes, Entada gigas, Salacia pynaerti and Tetrorchidium congolense were collected from the territory of Kenge, Bandundu (Democratic Republic of Congo, DRC). The collected plants were identified by experts of the herbarium of Kinshasa ( National Institute of Studies and Research in Agronomy, Department of Biology, Faculty of Science, University of Kinshasa, DR Congo ) and Professor Lukoki. They were dried at the room temperature. Once in the laboratory, the leaves were dried at $37^{\circ} \mathrm{C}$ in an oven while calculating the rate of moisture and were finely ground in a high-speed mill (Retsch ZM 100 Model) sieved at $180 \mu \mathrm{m}$ particle size. The powdered leaves were stored in the dark at room temperature and used for solvent extraction.

\section{Chemicals and reagents}

All solvents were of analytical grade and purchased from Merck (Germany) and VWR Chemicals Prolabo (Leuven, Belgium). Caffeic acid, gallic acid, rutin, hyperoside and isoquercitrin (HPLC grade); 2,2'-Azino-bis(3-ethylbenzothiazoline-6-sulphonic acid) (ABTS), 2-aminoethyldiphenylborat, dimethyl sulfoxide (DMSO), Folin-Ciocalteu reagent and potassium persulfate were purchased from Sigma (Bornem, Belgium). 1, 1-Diphenyl-2-picrylhydrazyl (DPPH) was purchased from Eastman Kodak (Rochester, NY, USA). Water was treated in a Milli-Q water ultrapurification system (Easy Pure Purification System) before use.

\section{Microscopic analysis}

Powder observations were made using lactic acid reagent (Steimetz reagent). ${ }^{7,8}$ Observations were made with a Hund WETZLAR microscope, and pictures were taken with Digital Camera CANON IXUS 165.

\section{Preparation of extracts}

Methanolic extracts were prepared by extracting successively $10 \mathrm{~g}$ of leaves powder with methanol HiPerSolv Chromanorm from VWR Chemicals Prolabo (Leuven, Belgium) to obtain $200 \mathrm{~mL}$ of percolate. Evaporation of the solvent was performed under reduced pressure $\left(40^{\circ} \mathrm{C}\right)$ followed by a $48-72 \mathrm{~h}$ vacuum drying to provide the dry extracts which were weighed and kept in hermetic and dark flasks at $4{ }^{\circ} \mathrm{C}$.

\section{Phytochemical analysis}

\section{Thin Layer Chromatography (TLC) analysis}

The phytochemical screening was performed following some standard lab techniques. ${ }^{9}$ Aqueous extracts at the concentration of $10 \mathrm{mg} / \mathrm{mL}$ were analyzed by TLC on normal phase Silica gel $60 \mathrm{~F}_{254}$ plates (Merck), using a $10 \mu \mathrm{L}$ deposit and as eluent either:

Ethyl acetate, formic acid, glacial acetic acid and water (100:11:11:26; $\mathrm{v} / \mathrm{v} / \mathrm{v} / \mathrm{v}$ )

Toluene/ethyl acetate $(9: 1 ; \mathrm{v} / \mathrm{v})$

Flavonoids and phenolic acids were revealed using Natural ProductsPEG reagent and observed under UV-365 nm light. Flavonoids were detected as yellow-orange fluorescent spots and phenolic acid as blue fluorescent spots. ${ }^{10}$ Chlorogenic acid, Kampferol 3-O-glucoside (astragalin), quercetin 3-O-galactoside (hyperoside), quercetin 3-O-rhamnoside (quercitrin) and quercetin 3-O-rutinoside (rutin) were used as standards.

\section{High-Performance Liquid Chromatography (HPLC-DAD) analysis}

Analytical HPLC- DAD separations were carried out on a Hypersil ODS RP18 column as described previously. ${ }^{11}$ Chlorogenic acid, rutin, and isoquercitrin were used as standards.

\section{Determination of total phenolic content}

Total phenolic content of methanolic extracts (Methanol 80\%) was determined according to the Folin-Ciocalteu method as described previously. ${ }^{12} \mathrm{~A}$ calibration curve of gallic acid $\left(0.025-0.4 \mathrm{mg} \mathrm{mL}^{-1}\right)$ was prepared, and phenolic contents were determined in triplicate from the linear regression equation of this curve. The results were expressed as milligrams of gallic acid (GA) equivalent per gram of dried matter.

\section{Flavonoid content}

The flavonoid content of the extracts was determined by UV-Vis spectrophotometry ${ }^{13}$ Results are expressed in mg equivalent of quercetin per $\mathrm{g}(\mathrm{mg} \mathrm{QE} / \mathrm{g})$ of dry vegetal material using the following equation $\mathrm{y}=$ $0.0232 \mathrm{x}+0.1535\left(\mathrm{R}^{2}=0.945\right)$.

\section{Tannins content}

The extraction of tannins was carried out according to the adapted method used by Zhang et al, 2008. ${ }^{14}$ Tannin extract contents were quantified by vanillin method using the procedure reported by Sun et al. $1998 .{ }^{15}$ This method is based on the ability of vanillin to react with tannins units in the presence of acid to produce a colored complex measured at 500 nm.

\section{Determination of anthocyanins}

The determination of the anthocyanin content of the extracts was performed by the procedure reported by Adedapo et al. ${ }^{16}$

\section{Evaluation of radical scavenging activity}

\section{ABTS radical scavenging capacity}

ABTS assay was based on the method described by Kapepula et al. ${ }^{17}$

\section{DPPH radical scavenging capacity}

DPPH assay was performed according to the method described previously by Floegel et al (2011) with slight modifications. ${ }^{18}$ A solution of $0.004 \%$ of DPPH in $80 \%(\mathrm{v} / \mathrm{v})$ methanol was prepared one hour before use. The absorbance of the solution was adjusted to $0.75 \pm 0.03$ at $517 \mathrm{~nm}$ using fresh $80 \%(\mathrm{v} / \mathrm{v})$ methanol. Then $0.02 \mathrm{~mL}$ of standard or sample were mixed with $1.98 \mathrm{~mL}$ of DPPH solution and incubated for $30 \mathrm{~min}$ in the dark covered with aluminum foil. The decrease of absorbance was monitored at $517 \mathrm{~nm}$ with Spectrophotometer Hewlett-Packard 8453. The antiradical capacity analysis was performed on dichloromethane and methanolic dry extracts. Quercetin was used as positive control and $\mathrm{ABTS}^{\bullet+}$, DPPH${ }^{\bullet}$ scavenging activities of extracts were expressed as $\mathrm{IC}_{50}$ ( $\mathrm{IC}_{50}$ is the amount of antioxidant necessary to decrease the initial concentration of radical by $50 \%)$.

\section{Statistical Analysis}

Results were expressed as mean values \pm standard deviation (SD). $\mathrm{IC}_{50}$ were calculated with GraphPad Prism 6.0 under application of the function "log (inhibitor) vs. normalized response-variable slope" after converting the concentrations into their decimal logarithm. One-way analysis (ANOVA) and Student's paired t-test were used to compare scavenging capacities determined by ABTS and DPPH assays and the level of statistical significance was set at $\mathrm{p}<0.05$, for two-sided testing. 


\section{RESULTS}

\section{Botanical microscopic characters}

Powders of the leaves of the different vegetables selected were treated with Steimetz reagent and showed the following specific botanical microscopic characters. Entada gigas revealed fragments of parenchyma with acicular raphides of calcium oxalate, rectangular epidermal cells containing crystals, paracytic stomata. Also reticulate vessels, smooth no glandular trichrome and few starch grains were observed (Figure 1).

Psophocarpus scandens leaves powder revealed abundant prisms of calcium oxalate, starch grains, fragments of lignified fibers, diacytic stomata, circular epidermal cells, spiral vessels and unicellular non grandular trichomes. Salacia pynaertii showed the presence of fibers containing crystals, epidermis fragments containing numerous paracytic stomata, cluster crystals (druse), spiral vessels, few starch grains and sclerotic cells (Figure 1). Leaf powder of Tetrochirdium congolense exhibited palisade parenchyma, anticlinal beaded cell walls, numerous anisocytic stomata, lipid droplets, unicellular nongrandular trichoma, punctuated vessels and fibers with crystals.

\section{Chemical analysis}

\section{Phytochemical screening}

The results of phytochemical screening showed that flavonoids, terpenes, steroids and quinones are present in all the species studied. However, E. gigas and P. scandes contain also alkaloids, S. pynaertii, and T. congolenses contain also anthocyanins. Iridoids were present in P.scandens and S. pynaertii.

TLC and HPLC-DAD analysis have shown the presence of polyphenolic compounds in all methanolic extracts. TLC fingerprints of extracts showed the presence of glycosylated flavonoids (yellow, orange and green fluorescent spots) and phenolic acids (blue fluorescent spots) as major compounds (Figure 2). This was confirmed by HPLC-DAD analysis (Figure 3). By comparison with the retention factor, the coloration of spots, retention time and UV-spectrum of standards used, some phenolic compounds could be identified in these extracts. E. gigas contains,
quercetin-3-O-rutinoside and kaempferol 3-O-glucoside; P. scandens contains quercetin 3-O-rhamnoside; S. pynaerti contains kaempferol 3-O-glucoside and T. congolense contains kaempferol 3-O-glucoside and quercetin 3-O-rhamnoside (quercitrin). Further chromatographic and spectroscopic studies are needed to characterize the others unknown compounds.

Results from the quantitative determination of anthocyanins, flavonoids, tannins, and total phenolic content are summarized in Table 1.

Anthocyanin and tannin contents were determined as catechin equivalents in milligrams per gram of dry weight (mg CE/g DW), while total polyphenol contents were calculated as gallic acid equivalents in milligrams per gram of dry weight (mg GAE/g DW). Flavonoid content was determined as quercetin equivalents in milligrams per gram of dry weight (QE/g DW). The total phenolic contents varied significantly (P $<0.05$ ) between the studied vegetables. Results showed that $S$. pynaertii is the vegetable with the highest amount of total phenolic compounds and anthocyanins. P. scandens had the highest amount of flavonoids. Furthermore, concentrations of tannins were also high in the studied vegetables, with higher values in $P$. scandens leaves, followed by the leaves of T. congolense.

\section{Antioxidant activity}

Radical scavenging activity of tested traditional food items, determined by two biochemical in vitro methods namely ABTS and DPPH assays is presented in Table 2 and is expressed as $\mathrm{IC}_{50}$ values.

$\mathrm{IC}_{50}$ is the amount of antioxidant necessary to decrease the initial concentration of radical by $50 \%$. Lower $\mathrm{IC}_{50}$ value indicates a higher antioxidant activity. Quercetin-equivalent $(\mathrm{QE})$ is calculated as $\mathrm{IC}_{50}$ of quercetin used as positive control divided by $\mathrm{IC}_{50}$ of plant extract. All the extracts had significant scavenging effects with antiradical activities connected to their ability to scavenge free radicals according to their $\mathrm{IC}_{50}$ and quercetin equivalent $(\mathrm{Q}-\mathrm{E})$ values. $\mathrm{IC}_{50}$ and $\mathrm{Q}-\mathrm{E}$ values for extracts showed that $S$. pynaertii is the most active followed by T. congolense, E. gigas and $P$. scandens in ABTS assay; while in DPPH assay, T. congolense is the most active.

Table 1: Total anthocyanins, flavonoids, tannins and total phenolic contents of selected vegetables.

\begin{tabular}{ccccc}
\hline Secondary metabolites & E. gigas & P. scandens & S. pynaertii & T. congolense \\
\hline $\begin{array}{c}\text { Anthocyanins (mg CE/g } \\
\text { DW) }\end{array}$ & nd & nd & $47.42 \pm 0,52$ & $37,73 \pm 0,25$ \\
Flavonoids (mg QE/g DW) & $37,08 \pm 1,02$ & $40,78 \pm 1,11$ & $31.62 \pm 2.17$ & $21,36 \pm 0,65$ \\
Tannins (mg CE/g DW) & $42,56 \pm 0,05$ & $102,56 \pm 0,08$ & nd & $100,89 \pm 0,08$ \\
Total phenolic content(mg & $54,74 \pm 0,49$ & $64,2 \pm 0,58$ & $508.34 \pm$ & $241,54 \pm 2,18$ \\
GAE/g DW) & & & 14,42 & \\
\hline
\end{tabular}

nd: not determined

Table 2: $I C_{50}$ values $(\mu \mathrm{g} / \mathrm{mL}$ ) and Q-E of methanolic extracts of selected traditional vegetables on ABTS and DPPH assays (Mean $\pm S D, n=6$ ).

\begin{tabular}{ccccc}
\hline Samples & \multicolumn{2}{c}{ ABTS } & DPPH \\
\cline { 2 - 5 } & $\mathbf{I C}_{\mathbf{5 0}}(\boldsymbol{\mu} \mathbf{g} / \mathrm{mL})$ & Q-E & IC $_{\mathbf{5 0}}(\boldsymbol{\mu g} / \mathbf{m L})$ & Q-E \\
\hline Entada gigas & $35,4 \pm 0,96$ & 0.04 & $45,5 \pm 0,97$ & 0.07 \\
Psophocarpus scandens & $53,2 \pm 0,97$ & 0.03 & $62,81 \pm 0,97$ & 0.05 \\
Salacia pynaertii & $2.11 \pm 0.48$ & 0.67 & $9.48 \pm 0.61$ & 0.34 \\
Tetrochirdium congolense & $3.65 \pm 1.03$ & 0.39 & $7.13 \pm 2.14$ & 0.45 \\
Quercetin & $1.42 \pm 0.40$ & & $3.21 \pm 0.99$ & \\
\hline
\end{tabular}




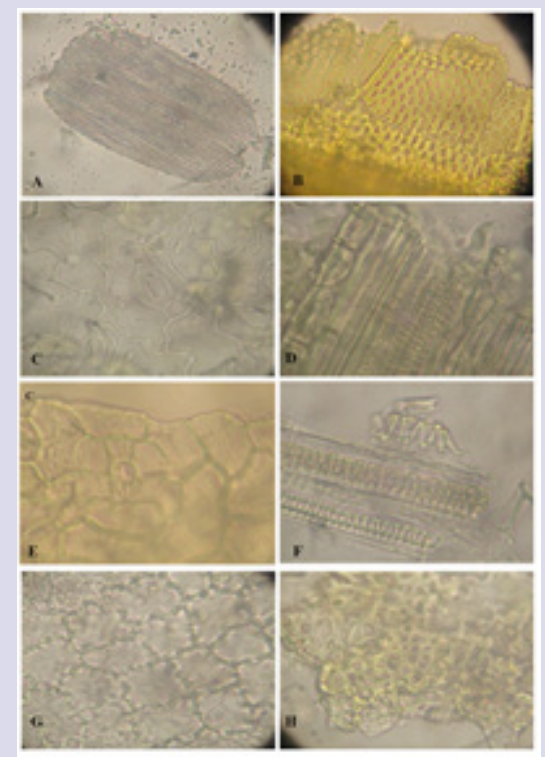

Figure 1: Raphides of calcium oxalate (A), Reticulate vessels (B) of Entada gigas; Diacytic stomata (C) and Spiral vassels, Prism of calcium oxalate (D) of Psophocarpus scandens; Paracytic stomata (E) and Spiral vessels (F) of Salacia pynaertii and Anticlinal beaded cell walls $(\mathrm{G})$ and Punctuated vessels $(\mathrm{H})$ of Tetrochirdium congolense at $40 \mathrm{X}$.

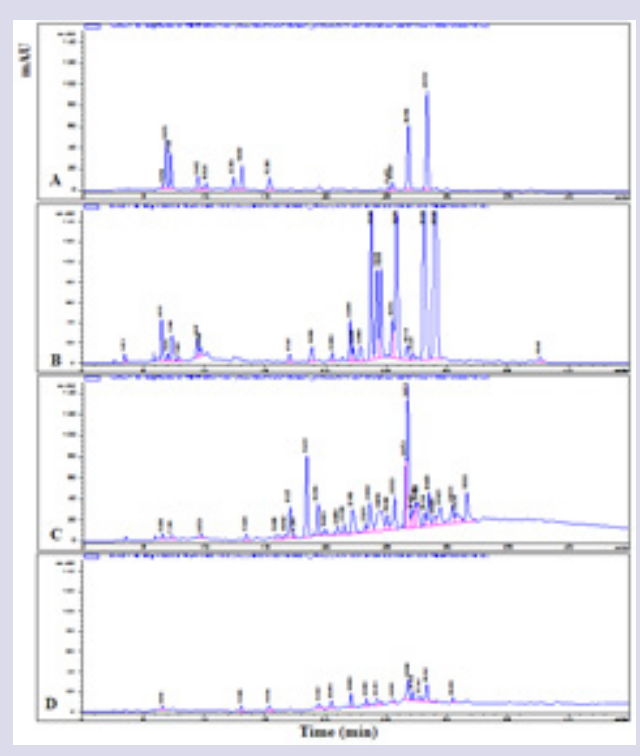

Figure 3: HPLC-DAD chromatograms of methanolic extracts from Entado gigas (A), Psophocarpus scandens (B), Salacia pynaertii (C) and, Tetrochirdium congolense (D) using a nonlinear gradient of acetonitrile $(A)$ and $0.05 \%$ trifluoroacetic acid in ultrapure water $(B): 0$ min, 0:100 (A:B), 1 min, 3:97(A:B); $45 \mathrm{~min}$, 40:60 (A:B); 46min, 0:100 (A:B) and $60 \mathrm{~min}$, stop at $1 \mathrm{~mL} / \mathrm{min}$ on Hypersil ODS column (4 $\mathrm{mm} \times 250 \mathrm{~mm}$ ) with detection at $340 \mathrm{~nm}$.

\section{DISCUSSION}

Considering the microscopic examination of the four vegetables, the presence or shape of specific crystals of calcium oxalate, grain starch, epidermal cells, fibers, cuticle, stomata, and vessels allowed the identification of these four species.

There is few reports on the phytochemical screening of these Congolese traditional vegetables. However, Fankam et al. ${ }^{20}$ Reported the presence

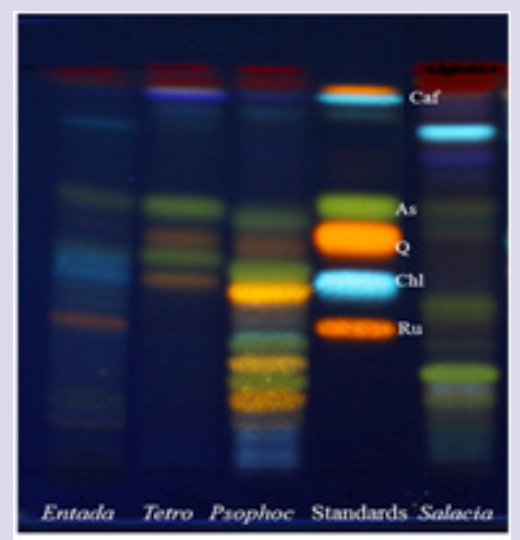

Figure 2: TLC chromatogram of methanolic extracts from E. gigas, $P$. scandens, S. pynaertii and T. congolense with astragalin (As), chlorogenic acid (Chl), quercitrin(Quer) and rutin(Rut) as standards; developed with ethyl acetate/ formic acid/glacial acetic acid/water (100:11:11:26; v/v/v/v) and visualized at $365 \mathrm{~nm}$ with Natural Products-PEG reagent. Flavonoids are detected as yellow-orange fluorescent spots and phenolic acids as blue fluorescent spots.

of alkaloids; phenols and tannins in E. gigas from Cameroon but flavonoids, quinones and terpenoids were not detected. Some studies showed that seeds from E. gigas used in the preparation of traditional concoction for curing diseases in Nigeria contained essential minerals and high amount of anti-nutrient factors such as oxalate, phytate, and tannins.,21 These anti-nutrient factors are reduced through processing of the vegetables. Oxalate content of leaves of E. gigas is in accordance with microscopic analysis that showed abundant fragments of parenchyma with cells containing calcium oxalate crystals. Previous studies on P. scandens, $S$. pynaertii and T. congolense reported their highest protein and mineral contents. ${ }^{2,22,23}$ Interestingly, $S$. pynaertii constitute the richest vegetable in methionine and cysteine among all studied traditional vegetables in Bandundu. ${ }^{24}$ Methionine and cysteine are sulphur amino acids, essential for the detoxification of cyanogen glycosides implicated in the occurrence of konzo. S. pynaertii is an unconventional green leafy vegetable consumed by populations of Popokabaka, another area severely affected by konzo. ${ }^{5}$

Many studies were performed to assess the nutritional value of $P$. scandens. Leaves of $P$. scandens were showed to contain lipids and proteins with high nutritive quality. One of the most important traditional use of this plant is to increase the quantity and quality of milk produced by nursing mothers. ${ }^{22}$ Our results obtained from ABTS and DPPH assays show that all the extracts possessed antioxidant properties. Our results were correlated between the two chemical methods used. The small differences observed between the two methods could be attributed to the fact that DPPH assay only detect hydrophilic antioxidants in the contrary of ABTS assay. The highest radical-scavenging capacity of S. pynaertii and T. congolense extracts is in adequacy with their higher total phenolic content.

Earlier studies have reported that the selected vegetables have a reasonable nutritive value. They are good source of essential amino acids and minerals especially for children who are exposed to many diseases., ${ }^{2,22,23}$ The high nutritive value of these traditional vegetables associated with their important antioxidant activities could contribute to a diversification of the diet in Bandundu's population, and could then provide benefits leading to a protection against oxidative damage under different conditions including konzo. 


\section{CONCLUSION}

The microscopic analysis of powders from leaves of selected species allowed the identification of specific botanical microscopic characters. TLC and HPLC-DAD analysis indicated that phenolic compounds are major secondary metabolites of leaves from E. gigas, P. scandens, S. pynaertii and T. congolense. All extracts exhibited good antioxidant activity with $S$. pynaertii and T. congolense as the most actives. However, these antioxidant in vitro activities should be complemented in the future by in vivo evaluation in healthy humans. Further studies are then needed to evaluate the cellular antioxidant and the in vivo antioxidant activities of these traditional vegetables and particularly in their cooked forms. This could lead to the valorization of these traditional vegetables, which could be promoted as food or as food supplements with high antioxidant capacity.

\section{ACKNOWLEDGEMENT}

The authors thank Professor Lukoki, Mr. Kikufi. A of Faculty of Sciences and Mr. Landu of the National Institute for Research in Agronomics (INERA), the University of Kinshasa for identification of the plants studied. They thank also the community of Kenge of their collaboration.

\section{CONFLICT OF INTEREST}

The authors declare that they have no conflict of interest.

\section{ABBREVIATION USED}

ABTS: 2,2'-Azino- bis (3-ethylbenzothiazoline-6-sulphonic acid; DPPH: 1, 1-Diphenyl-2-picrylhydrazyl; HPLC-DAD: High-Performance Liquid Chromatography with Diode-Array Detection; IC $_{50}:$ Half maximal Inhibitory Concentration; TLC: Thin Layer Chromatography.

\section{REFERENCES}

1. Marquardt KC, Watson RR. Polyphenols and Public Health. In: Polyphenols in Human Health and Disease. p. 9-15;2014.

2. Mbemba T, Remacle J, Paulus J, Anita A, Timi-Timi A, Kwilu N, et al. Aliments et denrées alimentaires traditionnels du Bandundu en R. D. Congo. Répertoire et composition en nutriments. 2013.

3. Makila-Mabe BG, Kikandau KJ, Sombo TM, Okitundu DL, Mwanza J-C, Boivin $\mathrm{MJ}$ et al. Serum 8,12-iso-iPF2 $\alpha$-VI Isoprostane Marker of Oxidative Damage and Cognition Deficits in Children with Konzo. PLoS ONE. 2014;9(9):e107191.

4. Ogungbenle HN, Oyadipe OT. Compositional and Amino Acid Profile of Nicker Bean ( Entada gigas ) Seeds. British Biotechnology Journal. 2015;6(2):43-50.

5. Ngudi DD, Banea-mayambu J, Lambein F, Kolsteren P. Konzo and dietary pattern in cassava-consuming populations of Popokabaka, Democratic Republic of Congo. Food and Chemical Toxicology. 2011;49(3):613-9.

6. Schmelzer GH, Gurib-Fakim A. Plant Resources of Tropical Africa 11(1). Medici- nal plants 1. PROTA Foundation, Wageningen, Netherlands. p. 2008:602-04Frederich M. Micrographie Appliquée à l'étude de la pharmacognosie. $3^{\text {eme }}$ BAC Pharmacie. Université de Liège. 2011. French.

7. Bukatuka F, Ngombe K, Mutwale K, Moni B, Makengo K, Pambu L et al. Bioactivity and Nutritional Values of Some Dioscorea Species Traditionally Used as Medicinal Foods in Bandundu, DR Congo. European Journal of Medicinal Plants. 2016;14(1):1-11.

8. Harbone JB. Phytochemical Methods. Chapman and Hall, Ltd. London. 1973

9. Wagner H, Bauer R, Melchart D, Xioa P-G, Staudinger A. Chromatographic Fingerprint Analysis of Herbal Medicinal: Thin-layer high performance liquid chromatography of chinese drugs. Springer International Publishing. 2013;267 p.

10. Tshilanda DD, Mutwale PK, Onyamboko DVN, Babady PB, Tsalu P, Tshibangu DST et al. Chemical Fingerprint and Anti-Sickling Activity of Rosmarinic Acid and Methanolic Extracts from Three Species of Ocimum from DR Congo. Journal of biosciences and Medicines. 2016;04:59-68.

11. Anagnostopoulou M, Kefalas P, Papageorgiou VP, Assimopoulou AN, Boskou D. Radical scavenging activity of various extracts and fractions of sweet orange peel (Citrus sinensis). Food Chemistry. 2006;94(1):19-25.

12. Quettier-deleu C, Gressier B, Vasseur J, Dine T, Brunet C, Luyckx M et al. Phenolic compounds and antioxidant activities of buckwheat ( Fagopyrum esculentum Moench ) hulls and flour. Journal of Ethnopharmacology. 2000;72(1):35-42.

13. Zhang $S$, Zheng $C$, Yan $X$, Tian W. Low concentration of condensed tannins from catechu significantly inhibits fatty acid synthase and growth of MCF-7 cells. Biochemical and Biophysical Research Communications. 2008;371(4):654-8.

14. Sun B, Ricardo-da-Silva JM, Spranger I. Critical Factors of Vanillin Assay for Catechins and Proanthocyanidins. Journal of Agricultural and Food Chemistry. 1998;46(10):4267-74.

15. Adedapo AA, Jimoh FO, Koduru S, Afolayan AJ, Masika PJ. Antibacterial and antioxidant properties of the methanol extracts of the leaves and stems of Calpurnia aurea. BMC Complementary and Alternative Medicine. 2008;8(1):1-8.

16. Kapepula PM, Mbombo PM, Franck F, Mouithys-Mickalad A, Mumba ND, Dibungi KP, Kabamba NN, Tits M, Frédérich M, Tamfum MJJ. Antioxidant potentiality of three herbal teas consumed in Bandundu rural areas of Congo. Natural Product Research.2017;31(16):1-4

17. Floegel A, Kim DO, Chung SJ, Koo SI, Chun OK. Comparison of ABTS/DPPH assays to measure antioxidant capacity in popular antioxidant-rich US foods. Journal of Food Composition and Analysis. 2011;24(7):1043-8.

18. Shailendra S.G, Nilambari S.G. Indian Herbal Drug Microscopy. Springer New York Heidelberg Dordrecht London. 2014.

19. Fankam AG, Kuiate JR, Kuete V. Antibacterial activities of Beilschmiedia obscura and six other Cameroonian medicinal plants against multi-drug resistant Gram-negative phenotypes. BMC Complementary and Alternative Medicine. $2014 ; 14(1): 241$.

20. Ogungbenle HN, Omodara OP. Physico Chemical and Fatty Acid Composition of Nicker Bean ( Entada gigas) Seed Oil. Advences in Analytical Chemistry. 2014;4(2):35-9.

21. Harder D, Lolema OPM, Tshisand M. Uses, nutritional composition, and ecogeography of four species of Psophocarpus (fabaceae, phaseoleae) in Zaire. Economic Botany. 1990;44(3):391-409.

22. Kambashi B, Boudry C, Picron P, Kiatoko H, Bindelle J. Feeding value of hays of tropical forage legumes in pigs: Vigna unguiculata, Psophocarpus scandens, Pueraria phaseoloides and Stylosanthes guianensis. Tropical Animal Health and Production. 2014;46(8):1497-502.

23. Alam MN, Bristi NJ, Rafiquzzaman M. Review on in vivo and in vitro methods evaluation of antioxidant activity. Saudi Pharmaceutical Journal. 2013;21(2):14352
PICTORIAL ABSTRACT

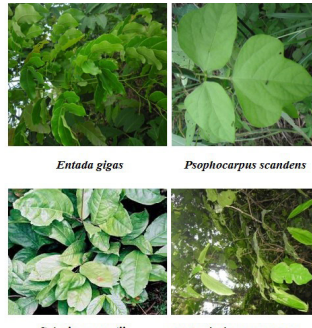

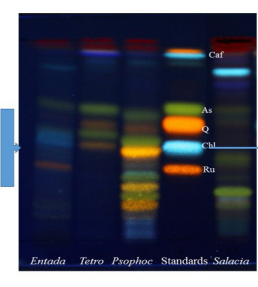

TLC chromatogram

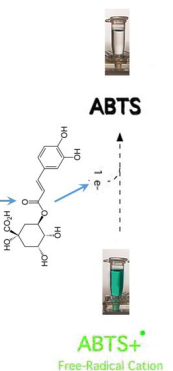

SUMMARY

- Unconventional green leafy vegetables have a high nutritive value and important antioxidant activity.

- Salacia pynaertii and Tetrorchidium congolense exhibited a high antioxidant activity with $\mathrm{IC}_{50}<10 \mu \mathrm{g} / \mathrm{mL}$.

- Antioxidant activity would depend on a synergic effect of several polyphenolic compounds.

- Studied vegetables could provide benefits in protecting against oxidative damage under different conditions including konzo. 


\section{ABOUT AUTHORS}

Ms Lydia Maganla Bahati: She is a Master student in Nutritional Epidemiology, B.Sc. in Molecular biologogy and searcher to the Faculty of Sciences of University of Kinshasa, Democratic Republic of Congo. Interested in adolescent girl's diet and health, her research involves phytochemistry studies into a variety of rich vegetables.

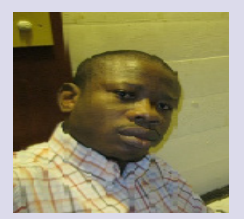

Mr Paulin Mutwale Kapepula: He is Ph D, Scientific staff and searcher to the Faculty of Pharmaceutical Sciences of University of Kinshasa, Democratic Republic of Congo. His research involves bioactivity and phytochemistry studies into a variety of plant species of DR Congo including mushrooms, wild tropical fruits. He works on the project "Traditional foods as putative nutraceuticals in konzo, a paralytic disease associated with oxidative stress and irreversible brain damage in sub-Saharan Africa. 